Oral presentation

Open Access

\title{
Trends in cancer incidence among HIV-infected persons in California, 1996-2006
}

\author{
MJ Silverberg*1, WA Leyden ${ }^{1}$, C Chao ${ }^{2}$, M Horberg1, D Klein ${ }^{3}$, W Towner ${ }^{4}$ \\ and DI Abrams 5
}

\begin{abstract}
Address: ${ }^{1}$ Kaiser Permanente Northern California, Division of Research, Oakland, California, USA, ${ }^{2}$ Kaiser Permanente Southern California, Department of Research \& Evaluation, Pasadena, California, USA, ${ }^{3}$ Kaiser Permanente Northern California, Hayward Medical Center, Hayward, California, USA, ${ }^{4}$ Kaiser Permanente Southern California, Los Angeles Medical Center, Los Angeles, California, USA and ${ }^{5}$ Hematology-Oncology Division, San Francisco General Hospital and University of California San Francisco, San Francisco, California, USA

* Corresponding author
\end{abstract}

from I I th International Conference on Malignancies in AIDS and Other Acquired Immunodeficiencies (ICMAOI): Basic, Epidemiologic, and Clinical Research

Bethesda, MD, USA. 6-7 October 2008

Published: 17 June 2009

Infectious Agents and Cancer 2009, 4(Suppl 2):O22 doi:I0.I I86/I750-9378-4-S2-O22

This abstract is available from: http://www.infectagentscancer.com/content/4/S2/O22

(C) 2009 Silverberg et al; licensee BioMed Central Ltd.

\section{Background}

Population-based surveillance for malignancies in HIVinfected patients in the antiretroviral therapy (ART) era is warranted given the aging population of patients and the high prevalence of risk factors in this population including tobacco use and viral co-infections.

\section{Methods}

We identified all adult HIV-infected persons enrolled in Kaiser Permanente (KP), an integrated health care system providing care to $\sim 25$ percent of all Californians in the most populated areas. Subjects at least 18 years of age at first enrollment after 1996 were included and followed until the earliest of an incident cancer diagnosis, last health plan enrollment, or the end of the study period (December 31, 2006). Incident AIDS-defining and nonAIDS-defining cancers were ascertained from the KP cancer registries, which participate in the California SEER program. Poisson regression was used to obtain age-adjusted calendar trends in cancer incidence from 1996 to 2006. Results are presented for KP Northern California only, but will be updated with additional data from KP Southern California.

\section{Results}

Between 1996 and 2006, 10,366 eligible HIV-infected persons were identified contributing 46,114 person-years.
Subjects were mostly male (90.2\%), with mean age 40 years and mean years known HIV+ of 4.1 years at study enrollment. Subjects were 59 percent Caucasian, 17 percent African-American, and 13 percent Latino. HIV exposure risk factor was 65 percent men who have sex with men, 15 percent heterosexual transmission, and 8 percent injection drug use. A total of 394 AIDS-defining cancers were identified consisting of 212 Kaposi's sarcomas (KS), 180 Non-Hodgkin's lymphomas (NHL), and two invasive cervical cancers. A total of 380 non-AIDS-defining cancers were identified. The most common non-AIDS-defining cancers were digestive and gastrointestinal (141), consisting primarily of anal (99), colorectal (22) and liver (12) cancers; genitourinary (54), consisting primarily of prostate (29) and kidney (9) cancers; head and neck cancers (24); gynecologic cancers other than cervix (18); Hodgkin's lymphoma (29); lung (43); and, melanoma (32). The AIDS-defining cancer rate/10,000 person-years declined from 128.7 in 1996-99 to 53.9 in 2004-06, corresponding to a relative rate (RR) per calendar year of 0.88 (95\% CI: 0.85, 0.92). KS and NHL showed similar declines. The non-AIDS-defining cancer rate increased from 78.9 percent in 1996 to 1999 to 97.3 percent in 2004 to 2006, corresponding to a RR per calendar year of 1.01 (95\% CI: 0.98, 1.04). Most individual non-AIDS-defining cancers showed a similar lack of a calendar trend in incidence. However, there was a suggestion of an increase dur- 
ing the ART era in colorectal cancers $(\mathrm{RR}=1.15 ; 95 \% \mathrm{CI}=$ $0.99,1.35)$ and genitourinary cancers $(R R=1.10 ; 95 \% \mathrm{CI}$ $=1.00,1.21$ ).

\section{Conclusion}

In the ART era, AIDS-defining cancers have declined and non-AIDS-defining cancer rates have generally remained stable. However, surveillance for non-AIDS-defining cancers should continue given the introduction of new therapeutic classes with the potential for oncogenic side effects, and the fact that HIV-infected patients continue to have increased rates of many cancers compared to the general population.
Publish with Biomed Central and every scientist can read your work free of charge

"BioMed Central will be the most significant development for disseminating the results of biomedical research in our lifetime. " Sir Paul Nurse, Cancer Research UK

Your research papers will be:

- available free of charge to the entire biomedical community

- peer reviewed and published immediately upon acceptance

- cited in PubMed and archived on PubMed Central

- yours - you keep the copyright

Submit your manuscript here:

http://www.biomedcentral.com/info/publishing_adv.asp 